\title{
GENETICS OF MENKES DISEASE
}

Fibroblast cultures from 12 unrelated patients with classical Menkes disease, an X-linked disorder of copper metabolism, were analyzed for mutations in the MNK gene at the Howard Hughes Medical Institute, University of California, San Francisco. Mutations were observed in 10 patients. Southern blot hybridization and reverse transcription-PCR should identify mutations in the majority of patients. (Das S et al. Diverse mutations in patients with Menkes disease often lead to exon skipping. Am I Hum Genet Nov 1994;55:883-889). (Reprints: Dr Seymour Packman, Department of Pediatrics, Division of Genetics, University of California, San Francisco, CA 94143).

COMMENT. The authors conclude that these studies should help to clarify the role of mutations leading to mild and atypical cases of Menkes disease, X-linked cutis laxa, and classical Menkes disease. Partial gene deletions have been observed in $15-20 \%$ of patients with Menkes disease. The majority of patients have the severe, classical symptoms of a progressive neurologic degeneration, connective-tissue defects, hypopigmentation, kinky hair, and death in early childhood. A deficiency of copper-containing enzymes results from a defect in copper transport.

\section{MUSCLE DISORDERS}

\section{GENETICS OF FUKUYAMA MUSCULAR DYSTROPHY}

The Fukuyama congenital muscular dystrophy (FCMD) chromosome analysis has been further defined at the University of Tokyo; Department of Pediatrics, Tokyo Women's Medical College; Kobe General Hospital; Aichi Welfare Center, Kasugai; and Nagoya City University Medical School, Japan. The FCMD locus was first mapped to chromosome 9q31-33 by genetic linkage analysis, and further defined with additional markers and families between loci D9S127 and CA246, a region that includes the mfd 220 locus. The close proximity of mfd220 to FCMD is supported by tight linkage disequilibrium. (Toda $\mathrm{T}$ et al. Refined mapping of a gene responsible for Fukuyama-type congenital muscular dystrophy: Evidence for strong linkage disequilibrium. Am I Hum Genet November 1994;55:946-950). (Reprints: Dr Tatsushi Toda, Department of Human Genetics, School of International Health, University of Tokyo, 7-3-1 Hongo, Bunkyo-ku, Tokyo 113, Japan).

COMMENT. Fukuyama-type congenital muscular dystrophy is an autosomal recessive disorder of muscle complicated by CNS anomalies and neuronal migration defects. It is the second most common form of childhood muscular dystrophy in Japan, and 1 in 100 persons is a carrier. Weakness of facial and limb muscles and generalized hypotonia are evident before 9 months, and most patients never walk. Severe mental and speech retardation occur simultaneously, and survival beyond 20 years is rare. The biochemical and cytogenetic defects are unknown. 